\title{
The effects of graft shrinkage and extrusion on early clinical outcomes after meniscal allograft transplantation
}

\author{
Jae-Hwa Kim, Soohyun Lee ${ }^{1}$, Doo Hoe Ha², Sang Min Lee ${ }^{2}$, Kyunghun Jung ${ }^{1}$ and Wonchul Choi ${ }^{1 *}$ (D
}

\begin{abstract}
Background: Graft shrinkage or radial extrusion is a reported complication after meniscus allograft transplantation (MAT). Whether shrinkage or extrusion progress after surgery and whether they are associated with the clinical outcome of MAT remain debatable. In this study, graft shrinkage and extrusion were measured in the coronal and sagittal planes using serial postoperative magnetic resonance imaging (MRI). The purpose of this study was to evaluate if graft shrinkage or extrusion is correlated to the clinical outcome of MAT.
\end{abstract}

Methods: MRIs acquired at 3 and 12 months postoperatively in 30 patients (21 men and 9 women) who underwent MAT (6 medial and 24 lateral menisci) from 2010 to 2016 were analyzed. Two orthopedic surgeons and two musculoskeletal specialized radiologists each performed the MRI measurements. Allograft shrinkage was measured by the width and thickness of the graft at the coronal and sagittal planes. To determine the graft extrusion, distances between the proximal tibia cartilage margin and the extruded graft margin were measured in both coronal (either lateral or medial) and sagittal (both anterior and posterior) plane and relative percentage of extrusion (RPE) were calculated. Subjective International Knee Documentation Committee (IKDC) scores at 12 months were evaluated as a clinical outcome measurement, and correlations between shrinkage or extrusion of allograft and IKDC score were analyzed.

Results: In the coronal plane, radial RPE averaged $43.6 \%$ at postoperative 3 months, but there was no significant progression of extrusion at 12 months (average $42.0 \%)(P=0.728)$. In the sagittal plane, there were no significant progressions of anterior and posterior RPE ( $P=0.487$ and 0.166 , respectively) between postoperative 3 and 12 months. Shrinkage was calculated by multiplying the width and height of the three sections and summing these values. There was no significant progression of shrinkage between postoperative 3 and 12 months $(P=0.150)$. RPE in the radial $(R=0.147, P=0.525)$, anterior $(R=0.249, P=0.264)$, and posterior $(R=0.230, P=0.315)$ directions and shrinkage ( $R=0.176, P=0.435)$ were not correlated to IKDC score at postoperative 12 months.

Conclusions: In the coronal and sagittal planes, extrusion and shrinkage did not progress from 3 months to 1 year. Extrusion and shrinkage had no correlation with early clinical outcomes. This finding suggests that graft extrusion or shrinkage may be not a great concern especially in early postoperative period of MAT, and multiple, serial MRI may be not necessary.

Keywords: Meniscus allograft transplantation, Extrusion, Shrinkage

\footnotetext{
* Correspondence: wcosdoc@gmail.com

${ }^{1}$ Department of Orthopaedic Surgery, CHA Bundang Medical Center, CHA

University, 351 Yatap-dong, Bundang-gu, Seongnam-si, Gyeonggi-do,

Republic of Korea

Full list of author information is available at the end of the article
}

(c) The Author(s). 2018 Open Access This article is distributed under the terms of the Creative Commons Attribution 4.0 International License (http://creativecommons.org/licenses/by/4.0/), which permits unrestricted use, distribution, and reproduction in any medium, provided you give appropriate credit to the original author(s) and the source, provide a link to the Creative Commons license, and indicate if changes were made. The Creative Commons Public Domain Dedication waiver (http://creativecommons.org/publicdomain/zero/1.0/) applies to the data made available in this article, unless otherwise stated. 


\section{Background}

The meniscectomized knee is associated with early onset of knee osteoarthritis due to a decrease in tibiofemoral contact area and an increase in joint contact pressures, especially among people who are physically active [1-4]. When treating meniscus injury patients, efforts are made to preserve the meniscus by meniscal repair or leave the meniscus as much as possible to prevent degenerative arthritis. However, not all meniscal tears can be repaired or saved, and total meniscectomy is often unavoidable. To address the problems of meniscectomized patients, there are ongoing efforts to develop techniques for meniscus regeneration or meniscus scaffold using tissue engineering strategies [5-7]. However, most of them are preclinical studies and evidences are limited to be a standard treatment option. On the other hand, meniscal allograft transplantation (MAT) has become an alternative treatment option in relatively young and active, but symptomatic, meniscectomized patients. Although evidence of cartilage protection after MAT and long-term studies are still insufficient, studies on MAT have shown pain reduction and functional improvement [8-10].

One of the known problems of MAT is extrusion or shrinkage of allograft. Several studies have reported that extrusion and shrinkage occur at various degrees after MAT by arthroscopic findings or analyses of serial magnetic resonance imaging (MRI) data after surgery $[9,11$, 12]. In addition, extrusion and shrinkage of the allograft after MAT may be a biomechanical disadvantage of the knee joint due to ineffective positioning of the allograft [13]. Therefore, adequate anatomic restoration and accurate sizing of the allograft are important for the transplant to function appropriately [14-17]. Whether extrusion or shrinkage progresses with time after surgery and whether they are associated with clinical outcome of MAT remain unclear. Moreover, graft extrusion has been evaluated mainly from the coronal plane, but rarely in the sagittal plane.

The purpose of this article is to evaluate whether extrusion or shrinkage of meniscal allograft progresses during short-term follow-up and to find out if the change of graft position or volume affects the clinical outcome. It was hypothesized that extrusion and shrinkage of the graft do not progress or affect the clinical outcome during short-term follow-up period.

\section{Methods}

Clinical and radiographic data of consecutive 50 patients who underwent MAT between 2010 and 2016 were prospectively collected. This study protocol was approved by our institutional review board, and informed consent was acquired from each patient. The indications for MAT were age $18 \leq$ years $\leq 50$, history of prior subtotal or total meniscectomy, persistent localized pain that did not resolve even after conservative treatment, well-aligned mechanical axis of lower extremity, correctable ligamentous stability, relatively healthy cartilage status (Outerbridge grade II or less), and preserved joint space (>

$2 \mathrm{~mm}$ ) on a $45^{\circ}$ of flexion weight-bearing posteroanterior radiograph. Contraindications for MAT were complete disappearance of the joint space or more than $5^{\circ}$ of mechanical axis deviation or uncorrected joint instability.

MRI scans acquired using a SIGNA ${ }^{\mathrm{TM}}$ HDxt 3T apparatus (GE Healthcare, Waukesha, WI, USA) were performed at 3 and 12 months postoperatively. The acceptable time limit for MRI at each time point was within 1 month. Patients were excluded if the time was exceeded. Among the 50 patients, 16 patients were excluded because they did not receive MRI according to the schedule. Also, one patient who underwent anterior cruciate ligament reconstruction at the same time as the MAT and three patients who underwent anterior cruciate ligament reconstruction before the MAT operation were excluded. Finally, 30 patients were included in the study.

The 30 patients consisted of 21 males and 9 females with an average age of 35 years (range, 18 to 50). The mean time interval between meniscectomy and MAT was 22 months (range, 6 to 74). Among them, 6 received medial and 24 received lateral meniscal transplantation (Table 1).

\section{Preoperative planning}

Plain radiographs were used to measure meniscal dimensions before surgery using the Pollard method [18]. In order to minimize the magnification error, a $100-\mathrm{mm}$ radiopaque rod was attached to the lateral epicondyle of the femur for anterior-posterior radiograph and perpendicularly to the center of the patella for lateral images. Fresh-frozen allograft of size within $10 \%$ of the measured value was prepared.

\section{Surgical technique}

All MAT procedures were performed by a single surgeon. Before the operation, the allografts were thawed in normal saline solution at room temperature. Medial menisci were transplanted using the double bone plug

Table 1 Demographics of patients

\begin{tabular}{ll}
\hline & Patients $(n=30)$ \\
\hline Age (years) & $35(18-54)$ \\
Gender (male:female) & $21: 9$ \\
Body mass index $\left(\mathrm{kg} / \mathrm{m}^{2}\right)$ & $25.5 \pm 1.7$ \\
Height $(\mathrm{cm})$ & $167.7 \pm 5.8$ \\
Weight $(\mathrm{kg})$ & $71.8 \pm 7.1$ \\
Lateral:medial MAT & $24: 6$ \\
Time from meniscectomy (months) & $15.8 \pm 19.3$ \\
\hline
\end{tabular}


technique, and lateral menisci were transplanted using the keyhole technique [19, 20]. Diagnostic arthroscopy was first performed to check the states of meniscus, ligaments, and cartilage. The remaining meniscus was removed to within 1-2 $\mathrm{mm}$ of the peripheral rim, and a bleeding bed was made using a shaver. For medial meniscus, tibial tunnels were reamed over the guidewires positioned in the anatomic anterior and posterior horn attachments. Each bone plug was anchored with a non-absorbable suture in advance. Three vertical mattress sutures were placed in the posterior horn, and two vertical mattress sutures were placed in the anterior horn at $5 \mathrm{~mm}$ intervals using inside-out repair technique. For the lateral meniscus, a keyhole slot parallel to the posterior tibial slope was made just under the lateral tibial spine. After the graft was introduced into the joint through the anterior mini-arthrotomy site, inside-out meniscal suture fixation was performed at $5 \mathrm{~mm}$ intervals.

\section{Postoperative care}

Immediately after surgery, patients were encouraged to perform quadriceps set and calf pumping as much as possible and straight leg raising exercise was begun 1 day after surgery. Two days after the operation, patients started passive knee range-of-motion exercise using continuous passive motion machine with hinged knee brace on. The goals were to achieve full extension within 1 week, $90^{\circ}$ of flexion within 3 weeks, and $120^{\circ}$ of flexion at 6 to 8 weeks. Toe-touch weight bearing with crutch was allowed up to 3 weeks and gradually increased to $50 \%$ of body weight until 6 weeks. Patients were then allowed full weight-bearing without crutches and hinged knee braces when one leg squatting was possible. Engaging in heavy exercise and competitive sports was prohibited until postoperative 1 year.

\section{Evaluation criteria}

All the radiographic measurements were done by two orthopedic surgeons and two musculoskeletal radiology specialists. One of the observers (SL) measured twice at 1-month interval to evaluate intra-observer reliability. Picture Archiving Communication System (Marosis, Infinity, Seoul, Republic of Korea) was used for the measurements. Anterior and posterior extrusions were measured in the mid-sagittal section, and the radial extrusion was measured in the mid-coronal section. The mid-coronal and mid-sagittal sections were pre-determined under the agreement of observers and each observer measured from the same section. The extrusion was defined as the distance between the outer edge of the articular cartilage of the tibial plateau and the outer edge of the meniscus. The relative percentage of extrusion (RPE) of anterior (RPEa), posterior (RPEp), and radial (RPEr) directions were calculated to evaluate the degree of extrusion (Fig. 1). The intruded meniscus was described as negative value. Shrinkage was evaluated by measuring the height and width of the meniscus in each sections and multiplying them to estimate the volume. Subjective International Knee Documentation Committee (IKDC) scores at preoperative and postoperative 1-year periods were recorded as clinical outcome measurements.

\section{Data analyses}

Statistical analyses were performed using SPSS 16.0 for Windows (SPSS, IBM, Chicago, Illinois, USA), with $P<$ 0.05 considered statistically significant. The inter- and intra-observer reliabilities of measurements were analyzed by intra-class correlation coefficient (ICC). Change of anterior, posterior, radial RPE and shrinkage between 3 and 12 months after MAT were analyzed by paired $t$ test. Also, the difference between preoperative and postoperative 1 year subjective IKDC scores was compared using paired $t$ test. The differences of RPE and shrinkage between the medial and lateral menisci were analyzed by Mann-Whitney $U$ test. Correlations between demographics or radiographic measurements and IKDC score were analyzed using Pearson's correlation analysis.

\section{Results}

Inter- and intra-observer reliabilities of extrusion and shrinkage were excellent (Table 2). There were no significant progressions of anterior $(P=0.487)$ and posterior RPE $(P=0.166)$ between postoperative 3 and 12 months. Also, in the coronal plane, there was no significant progression of radial RPE between postoperative 3 and 12 months $(P=0.728)$. Shrinkage was calculated by multiplying the width and height of the three sections and adding them together, and there was no significant progression of shrinkage between postoperative 3 and 12 months $(P=0.150)$ (Table 3$)$.

Preoperative subjective IKDC score (average $37.7 \pm$ 12.4 points, range 18 to 50 points) significantly improved after 1 year (average $69.0 \pm 11.9$ points, range 50 to 92 points $)(P<0.001)$.

The difference in RPE changes and shrinkage between 6 medial and 24 lateral MATs were compared. There was no statistical difference in progression of anterior $(P$ $=0.823)$, posterior $(P=0.218)$, and radial $(P=0.576)$ extrusion between the medial and lateral directions. Shrinkage was also statistically insignificant $(P=0.145)$ (Fig. 2).

RPE in radial ( $R=0.147, P=0.525)$, anterior $(R=0.249$, $P=0.264)$, and posterior $(R=0.230, P=0.315)$ directions and shrinkage $(R=0.176, P=0.435)$ were not correlated to IKDC scores at postoperative 12 months. Possible confounding factors that can influence the clinical outcome including age, sex, body mass index, laterality of 


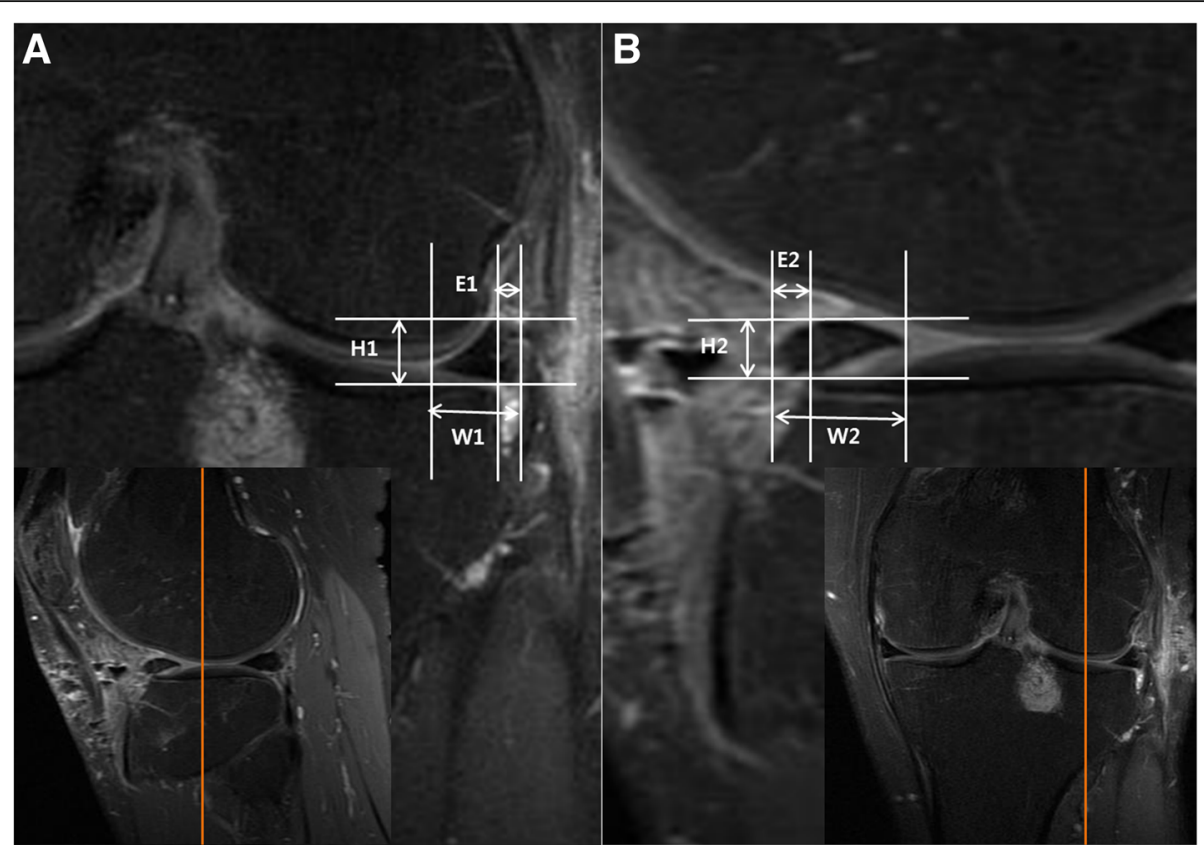

Fig. 1 Measurements of graft extrusion or intrusion in the mid-sagittal plane and mid-coronal plane. From the mid-coronal knee MRI section (a), the radial extrusion (E1) was measured as the distance between the outer edge of the articular cartilage of the tibial plateau and the outer edge of the allograft. Also, the height ( $\mathrm{H} 1)$ and the width (W1) of the graft were measured. The radial relative percentage of extrusion (RPEr) was defined as the percentage of the width of extrusion relative to the width of the entire allograft $(E 1 / W 1 \times 100)$. Similarly, the anterior relative percentage of extrusion (RPEa) was calculated after measuring the anterior extrusion (E2) and graft width (W2) from the mid-sagittal section (b). Graft height in sagittal section $\left(\mathrm{H}_{2}\right)$ was also measured. Extrusion was expressed as a positive value and intrusion as a negative value

MAT (medial or lateral), or time from previous meniscectomy did not show any significant correlation.

\section{Discussion}

In this study, the graft extrusion and shrinkage did not progress between 3 months and 1 year period after MAT in both coronal and sagittal planes. In addition, shrinkage and extrusion of the graft were not related to early clinical outcomes of MAT.

Table 2 Intra-class correlation coefficients (ICC) for measurement of relative percentage of extrusion (RPE) and shrinkage

\begin{tabular}{llll}
\hline & Months & Inter-observer ICC & Intra-observer ICC \\
\hline RPEa $^{a}$ & 3 & $0.897(0.806-0.946)$ & $0.928(0.897-0.952)$ \\
& 12 & $0.871(0.758-0.936)$ & $0.947(0.934-0.959)$ \\
RPEp $^{\text {b }}$ & 3 & $0.900(0.812-0.950)$ & $0.917(0.895-0.924)$ \\
& 12 & $0.863(0.740-0.933)$ & $0.888(0.796-0.902)$ \\
RPEr $^{c}$ & 3 & $0.954(0.914-0.977)$ & $0.966(0.953-0.978)$ \\
& 12 & $0.921(0.851-0.962)$ & $0.918(0.897-0.926)$ \\
Shrinkage & 3 & $0.935(0.878-0.968)$ & $0.976(0.966-0.990)$ \\
& 12 & $0.914(0.839-0.957)$ & $0.944(0.929-0.955)$ \\
\hline
\end{tabular}

Values are expressed as ICC and $95 \% \mathrm{Cl}$ in parentheses

${ }^{a} R P E a$ relative percentage of extrusion at anterior meniscus

${ }^{\mathrm{b}} R P E p$ relative percentage of extrusion at posterior meniscus

${ }^{\mathrm{C}} R P E$ r relative percentage of extrusion at radial meniscus
Graft shrinkage is a potential complication of MAT and understood as a change in the graft property during the remodeling process, and several studies have shown that meniscal allografts lose normal collagen architecture during early remodeling periods, and a loss of microarchitecture may cause morphologic alterations [13, 21, 22]. Although it has been regarded as a less frequent problem with the advent of the current (deep-frozen) preservation technique, few studies reported the shrinkage still occurs with deep-frozen grafts [21]. Moreover, studies on the effect of graft shrinkage on the clinical outcome after MAT are surprisingly rare, and it is still unclear whether the graft shrinkage is a progressive phenomenon. A laboratory study by Dienst et al. [14] showed that undersized graft causes increased forces across the articular cartilage and allograft itself. A serial

Table 3 Progression of relative percentage of extrusion (RPE) and shrinkage

\begin{tabular}{llll}
\hline & 3 months & 12 months & $P$ \\
\hline RPEa & $40.3 \pm 4.6$ & $41.7 \pm 5.4$ & 0.487 \\
RPEp & $-27.7 \pm 6.1$ & $-21.2 \pm 5.6$ & 0.166 \\
RPEr & $43.6 \pm 3.1$ & $42.0 \pm 3.7$ & 0.728 \\
Shrinkage & $172.0 \pm 8.2$ & $180.6 \pm 11.5$ & 0.150 \\
\hline
\end{tabular}

Values are expressed as mean \pm SD unless otherwise indicated 

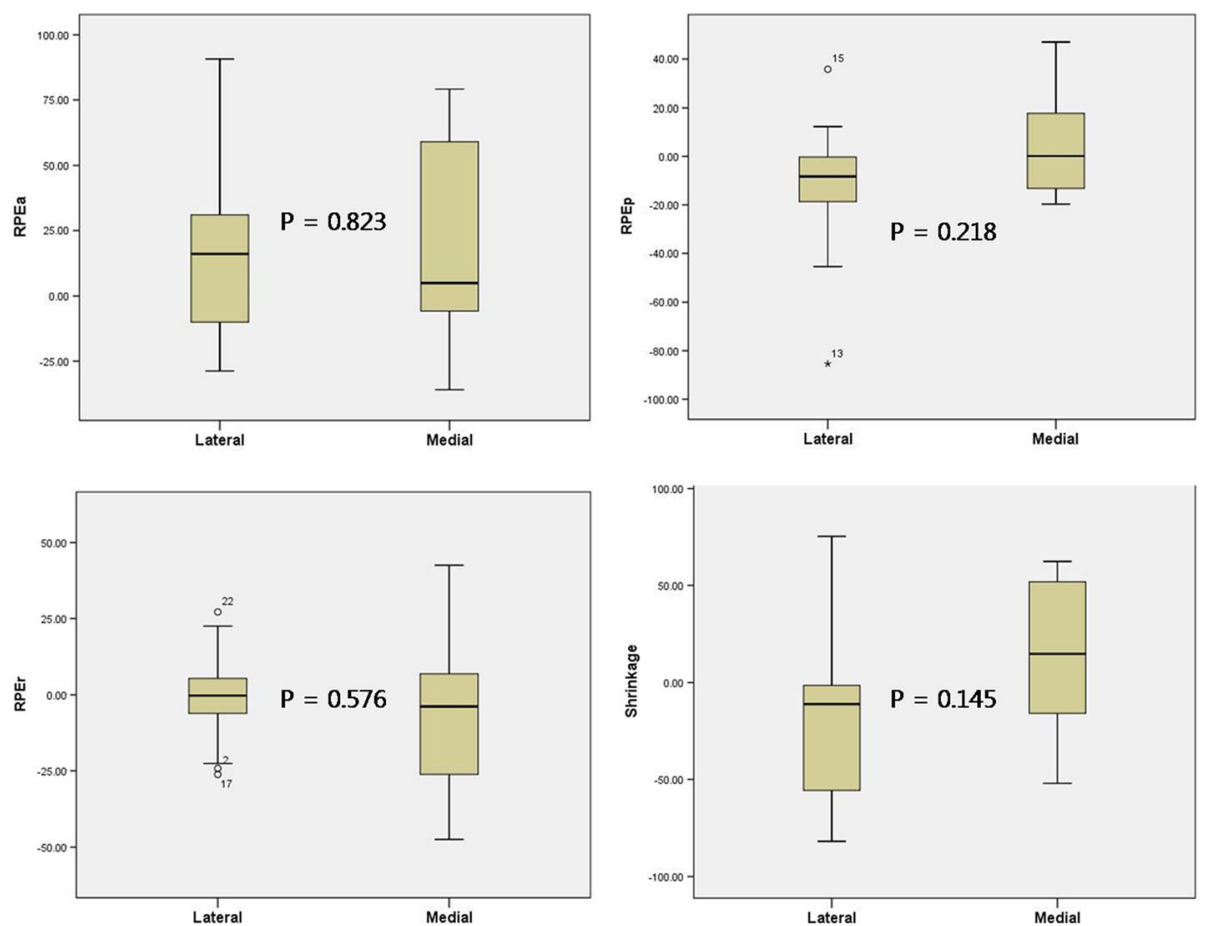

Fig. 2 Comparison of extrusion and shrinkage progression between medial and lateral meniscal allograft transplantation

MRI study by Lee et al. [23] reported that although $65 \%$ of cases showed graft shrinkage, it occurred during the first 3 months but stabilized thereafter. Another serial MRI study by Carter and Economopoulos [24] reported that graft shrinkage was observed until 6 months after MAT. In our study, there was no significant progression of shrinkage after 3 months and shrinkage showed no effect on the clinical outcome after 1 year of surgery. This finding suggests that shrinkage may be an initial or early phenomenon after surgery caused by micro-architectural remodeling, but does not progress after the remodeling ends.

The extrusion of the graft is regarded as another complication after MAT, and relatively more studies have investigated this issue compared to the shrinkage. Several studies have investigated the change of graft extrusion after MAT using serial MRI. Lee et al. [25] found that the graft extrusion occurred in early ( $<6$ weeks) after MAT, while it did not progress until postoperative 1 year. Recently, a mid-term follow-up study reported that early (<6 weeks) graft extrusion did not progress until 3- to 5-year MRI follow-up [26]. In addition, $\mathrm{Ha}$ et al. [27] reported no significant difference in graft extrusion between 1 and 4 years after MAT. It is noteworthy that the graft extrusion was evaluated from both coronal and sagittal MRI images. Most of the studies focused on the graft extrusion in radial direction observed on coronal plane, while only few studies from the same study group $[26,28]$ evaluated the graft extrusion in anterior or posterior direction. In our study, the graft extrusion in both coronal and sagittal directions did not progress between 3 months and 1 year post-MAT. Based on this finding, it is supposed that the graft "extrusion" may be not a progressive problem, but rather may be a problem that already existed immediately after surgery due to assumed reasons including graft size mismatch or inadequate graft position. There were studies on efforts to prevent graft extrusion by reducing the graft size [29] or using different approach for graft placement [30-32]. In this respect, the authors recently modified medial MAT technique as tensioning the anterior horn of the graft using suture anchor after bone fixation (unpublished data).

Association between the extrusion of native meniscus and progression of symptomatic knee osteoarthritis has been reported [33-35]. However, many studies on the extrusion after MAT reported that the extent of extrusion did not correlate with the clinical outcomes, although they have confirmed the occurrence of extrusion $[26,28,36,37]$. Our study result is in accordance with previous MAT studies that even though the graft extrusion was observed, there was no significant correlation between the extrusion and the clinical outcome.

The difference in progression of extrusion and shrinkage between the medial and lateral MAT cases was also compared, and no significant difference was found out. Although there were reports showing more graft extrusion after medial MAT compared to lateral MAT $[28,38]$, it has not been studied if there are any differences in the progression of extrusion or shrinkage 
between lateral and medial MATs. However, this issue was not one of our study purposes and our finding cannot be generalized since it may be underpowered with considerably different number of lateral and medial MAT cases.

This study has some limitations. First, the follow-up period was relatively short to evaluate the long-term clinical outcomes of the procedure. Second, the possible early change of the graft within weeks after MAT could not be evaluated, since MRI was first taken 3 months after the surgery. It would be beneficial as reference if immediate postoperative MRI was available. However, it was concerned that early postoperative changes including increased joint effusion, soft tissue swelling may obscure accurate MRI evaluation. In addition, it may be difficult for patient to maintain an adequate position to take MRI at immediate postoperative period. Third, the accuracy of determining the meniscal margin on sagittal images is known to be lower than the measurement from coronal images [39]. Four observers measured all parameters in same, predetermined sections to compensate this possible error, and inter- and intra-observer reliabilities were excellent in our study.

\section{Conclusion}

In the coronal and sagittal planes, extrusion and shrinkage did not progress from 3 months to 1 year after meniscal allograft transplantation. This finding suggests that graft extrusion or shrinkage is not progressive, but rather is a static phenomenon. Not the characteristics of the graft itself, but the techniques for graft sizing, fixation, and positioning may be determinants of the early graft change after MAT. In addition, shrinkage and extrusion of the graft did not correlate with early clinical outcomes of MAT. Therefore, multiple, serial MRI may be not necessary in early period after MAT, even though the graft extrusion or shrinkage occurs. However, future studies will be required to determine the effects of the graft extrusion or shrinkage on long-term clinical outcome of MAT.

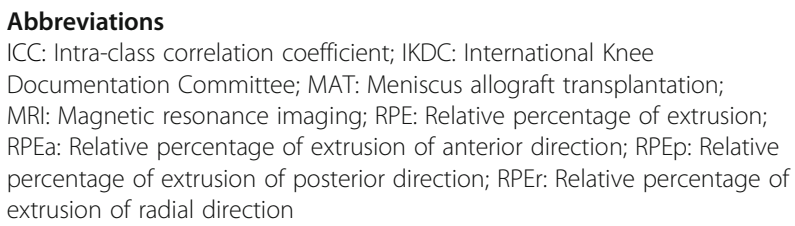

\section{Availability of data and materials}

The authors confirm that all data underlying the findings are fully available from the corresponding author on reasonable request.

\section{Authors' contributions}

J-HK and WC contributed to the study design, data analysis, and manuscript preparation. SL contributed to the data collection and manuscript preparation. $\mathrm{DHH}$ and SML contributed to the data collection and data analysis. KJ contributed to the data collection. All authors read and approved the final manuscript.

\section{Ethics approval and consent to participate}

All procedures performed in studies were in accordance with the ethical standards of the institutional and/or national research committee and with the 1964 Helsinki Declaration and its later amendments or comparable ethical standards. The study protocol was approved by our institutional review board (CHA Bundang Medical Center, CHA University), and informed consent was acquired from each patient.

\section{Consent for publication}

Not applicable.

\section{Competing interests}

This manuscript has not been published elsewhere in part or in entirety and is not under consideration by another journal. The authors declare that they have no competing of interests.

\section{Publisher's Note}

Springer Nature remains neutral with regard to jurisdictional claims in published maps and institutional affiliations.

\section{Author details}

${ }^{1}$ Department of Orthopaedic Surgery, CHA Bundang Medical Center, CHA University, 351 Yatap-dong, Bundang-gu, Seongnam-si, Gyeonggi-do, Republic of Korea. ${ }^{2}$ Department of Radiology, CHA Bundang Medical Center, CHA University, 351 Yatap-dong, Bundang-gu, Seongnam-si, Gyeonggi-do, Republic of Korea.

Received: 25 March 2018 Accepted: 12 July 2018

Published online: 20 July 2018

References

1. Longo UG, Ciuffreda M, Candela V, Rizzello G, D'Andrea V, Mannering N, Berton A, Salvatore G, Denaro V. Knee osteoarthritis after arthroscopic partial meniscectomy: prevalence and progression of radiographic changes after 5 to 12 years compared with contralateral knee. J Knee Surg. 2018; [Epub ahead of print]

2. Stein T, Mehling AP, Welsch F, von Eisenhart-Rothe R, Jager A. Long-term outcome after arthroscopic meniscal repair versus arthroscopic partial meniscectomy for traumatic meniscal tears. Am J Sports Med. 2010;38: 1542-8.

3. Verdonk R, Madry H, Shabshin N, Dirisamer F, Peretti GM, Pujol N, Spalding $T$, Verdonk $P$, Seil $R$, Condello $V$, et al. The role of meniscal tissue in joint protection in early osteoarthritis. Knee Surg Sports Traumatol Arthrosc. 2016; 24:1763-74.

4. Xu C, Zhao J. A meta-analysis comparing meniscal repair with meniscectomy in the treatment of meniscal tears: the more meniscus, the better outcome? Knee Surg Sports Traumatol Arthrosc. 2015;23:164-70.

5. Pillai MM, Gopinathan J, Selvakumar R, Bhattacharyya A. Human knee meniscus regeneration strategies: a review on recent advances. Curr Osteoporos Rep. 2018;16:224-35.

6. Bilgen $B$, Jayasuriya $C T$, Owens BD. Current concepts in meniscus tissue engineering and repair. Adv Healthc Mater. 2018;7:e1701407.

7. Dangelmajer S, Familiari F, Simonetta R, Kaymakoglu M, Huri G. Meniscal transplants and scaffolds: a systematic review of the literature. Knee Surg Relat Res. 2017:29:3-10.

8. Rosso F, Bisicchia S, Bonasia DE, Amendola A. Meniscal allograft transplantation: a systematic review. Am J Sports Med. 2015;43:998-1007.

9. Samitier G, Alentorn-Geli E, Taylor DC, Rill B, Lock T, Moutzouros V, Kolowich P. Meniscal allograft transplantation. Part 2: systematic review of transplant timing, outcomes, return to competition, associated procedures, and prevention of osteoarthritis. Knee Surg Sports Traumatol Arthrosc. 2015;23: 323-33.

10. Rongen JJ, Hannink G, van Tienen TG, van Luijk J, Hooijmans CR. The protective effect of meniscus allograft transplantation on articular cartilage: a systematic review of animal studies. Osteoarthr Cartil. 2015;23:1242-53.

11. Verdonk PC, Verstraete KL, Almqvist KF, De Cuyper K, Veys EM, Verbruggen G, Verdonk R. Meniscal allograft transplantation: long-term clinical results 
with radiological and magnetic resonance imaging correlations. Knee Surg Sports Traumatol Arthrosc. 2006;14:694-706.

12. Ahn JH, Kang HW, Yang TY, Lee JY. Multivariate analysis of risk factors of graft extrusion after lateral meniscus allograft transplantation. Arthroscopy. 2016;32:1337-45.

13. Samitier G, Alentorn-Geli E, Taylor DC, Rill B, Lock T, Moutzouros V, Kolowich P. Meniscal allograft transplantation. Part 1: systematic review of graft biology, graft shrinkage, graft extrusion, graft sizing, and graft fixation. Knee Surg Sports Traumatol Arthrosc. 2015;23:310-22.

14. Dienst M, Greis PE, Ellis BJ, Bachus KN, Burks RT. Effect of lateral meniscal allograft sizing on contact mechanics of the lateral tibial plateau: an experimental study in human cadaveric knee joints. Am J Sports Med. 2007;35:34-42.

15. Lee DH, Kim JM, Lee BS, Kim KA, Bin SI. Greater axial trough obliquity increases the risk of graft extrusion in lateral meniscus allograft transplantation. Am J Sports Med. 2012:40:1597-605.

16. Sekaran SV, Hull ML, Howell SM. Nonanatomic location of the posterior horn of a medial meniscal autograft implanted in a cadaveric knee adversely affects the pressure distribution on the tibial plateau. Am J Sports Med. 2002:30:74-82.

17. von Lewinski G, Kohn D, Wirth CJ, Lazovic D. The influence of nonanatomical insertion and incongruence of meniscal transplants on the articular cartilage in an ovine model. Am J Sports Med. 2008;36:841-50.

18. Pollard ME, Kang Q, Berg EE. Radiographic sizing for meniscal transplantation. Arthroscopy. 1995;11:684-7.

19. Lee DW, Park JH, Chung KS, Ha JK, Kim JG. Arthroscopic lateral meniscal allograft transplantation with the key-hole technique. Arthrosc Tech. 2017;6: e1815-20.

20. Lee DW, Park JH, Chung KS, Ha JK, Kim JG. Arthroscopic medial meniscal allograft transplantation with modified bone plug technique. Arthrosc Tech. 2017;6:e1437-42.

21. Mickiewicz P, Binkowski M, Bursig H, Wrobel Z. Preservation and sterilization methods of the meniscal allografts: literature review. Cell Tissue Bank. 2014; 15:307-17.

22. Hommen JP, Applegate GR, Del Pizzo W. Meniscus allograft transplantation: ten-year results of cryopreserved allografts. Arthroscopy. 2007;23:388-93.

23. Lee BS, Chung JW, Kim JM, Cho WJ, Kim KA, Bin SI. Morphologic changes in fresh-frozen meniscus allografts over 1 year: a prospective magnetic resonance imaging study on the width and thickness of transplants. Am J Sports Med. 2012;40:1384-91.

24. Carter T, Economopoulos KJ. Meniscal allograft shrinkage-MRI evaluation. J Knee Surg. 2013;26:167-71.

25. Lee DH, Kim TH, Lee SH, Kim CW, Kim JM, Bin SI. Evaluation of meniscus allograft transplantation with serial magnetic resonance imaging during the first postoperative year: focus on graft extrusion. Arthroscopy. 2008;24:111521.

26. Kim NK, Bin SI, Kim JM, Lee CR, Kim JH. Meniscal extrusion does not progress during the midterm follow-up period after lateral meniscal transplantation. Am J Sports Med. 2017;45:900-8.

27. Ha JK, Jang HW, Jung JE, Cho SI, Kim JG. Clinical and radiologic outcomes after meniscus allograft transplantation at 1-year and 4-year follow-up Arthroscopy. 2014;30:1424-9.

28. Lee $\mathrm{DH}$, Lee CR, Jeon JH, Kim KA, Bin Sl. Graft extrusion in both the coronal and sagittal planes is greater after medial compared with lateral meniscus allograft transplantation but is unrelated to early clinical outcomes. Am J Sports Med. 2015;43:213-9.

29. Jang SH, Kim JG, Ha JG, Shim JC. Reducing the size of the meniscal allograft decreases the percentage of extrusion after meniscal allograft transplantation. Arthroscopy. 2011;27:914-22.

30. Kim YS, Kang KT, Son J, Kwon OR, Choi YJ, Jo SB, Choi YW, Koh YG. Graft extrusion related to the position of allograft in lateral meniscal allograft transplantation: biomechanical comparison between parapatellar and transpatellar approaches using finite element analysis. Arthroscopy. 2015;31: 2380-2391.e2382.

31. Yoon JR, Kim TS, Lee YM, Jang HW, Kim YC, Yang JH. Transpatellar approach in lateral meniscal allograft transplantation using the keyhole method: can we prevent graft extrusion? Knee Surg Sports Traumatol Arthrosc. 2011;19: $214-7$.

32. Ren S, Zhang X, You T, Jiang X, Jin D, Zhang W. Clinical and radiologic outcomes after a modified bone plug technique with anatomical meniscal root reinsertion for meniscal allograft transplantation and a minimum 18month follow-up. J Orthop Surg Res. 2018;13:97.
33. Berthiaume MJ, Raynauld JP, Martel-Pelletier J, Labonte F, Beaudoin G, Bloch DA, Choquette D, Haraoui B, Altman RD, Hochberg M, et al. Meniscal tear and extrusion are strongly associated with progression of symptomatic knee osteoarthritis as assessed by quantitative magnetic resonance imaging. Ann Rheum Dis. 2005;64:556-63.

34. Furumatsu T, Kodama Y, Kamatsuki Y, Hino T, Okazaki Y, Ozaki T. Meniscal extrusion progresses shortly after the medial meniscus posterior root tear. Knee Surg Relat Res. 2017;29:295-301.

35. Kaplan DJ, Alaia EF, Dold AP, Meislin RJ, Strauss EJ, Jazrawi LM, Alaia MJ. Increased extrusion and ICRS grades at 2-year follow-up following transtibial medial meniscal root repair evaluated by MRI. Knee Surg Sports Traumatol Arthrosc. 2017;

36. Ha JK, Shim JC, Kim DW, Lee YS, Ra HJ, Kim JG. Relationship between meniscal extrusion and various clinical findings after meniscus allograft transplantation. Am J Sports Med. 2010:38:2448-55.

37. Lee BS, Chung JW, Kim JM, Kim KA, Bin SI. Width is a more important predictor in graft extrusion than length using plain radiographic sizing in lateral meniscal transplantation. Knee Surg Sports Traumatol Arthrosc. 2012; 20:179-86.

38. Yoon KH, Lee SH, Park SY, Kim HJ, Chung KY. Meniscus allograft transplantation: a comparison of medial and lateral procedures. Am J Sports Med. 2014:42:200-7.

39. Hunter DJ, Zhang YQ, Niu JB, Tu X, Amin S, Clancy M, Guermazi A, Grigorian $M$, Gale D, Felson DT. The association of meniscal pathologic changes with cartilage loss in symptomatic knee osteoarthritis. Arthritis Rheum. 2006;54: 795-801.

\section{Ready to submit your research? Choose BMC and benefit from:}

- fast, convenient online submission

- thorough peer review by experienced researchers in your field

- rapid publication on acceptance

- support for research data, including large and complex data types

- gold Open Access which fosters wider collaboration and increased citations

- maximum visibility for your research: over $100 \mathrm{M}$ website views per year

At BMC, research is always in progress.

Learn more biomedcentral.com/submissions 